\title{
Livros didáticos para o ensino de Arte escolar: cultura Afro-brasileira e Indígena
}

\section{Textbooks for School Art Teaching: Afro-Brazilian and Indigenous culture}

\author{
Dorcas Weber \\ Universidade Federal do Rio Grande do Sul
}

\begin{abstract}
Resumo
Livros didáticos constituem artefatos culturais que fazem parte da memória daqueles que, por algum momento, vivenciaram a educação escolar. Aqui, este artefato é objeto de investigação com foco naqueles disponibilizados pelo PNLD 2017 às escolas públicas brasileiras para a disciplina Arte. O objetivo desta pesquisa foi de perceber a presença do conteúdo história e cultura Afro-brasileira e Indígena e as possibilidades de trabalho para o ensino de Arte apresentadas nessas produções, levando em conta a Proposta Triangular. Palavras-chave: Ensino de Arte. Livro didático. História e cultura afro-brasileira e indígena.
\end{abstract}

\begin{abstract}
Textbooks are cultural artifacts that form part of the memory of those who, for some time, experienced school education. Here, this artifact is the subject of research focusing on those made available by PNLD 2017 to Brazilian public schools for the Art discipline. The objective of this research was to perceive the presence of the Afro-Brazilian and Indigenous history and culture contents and the possibilities of work for the teaching of Art presented in these productions, taking into account the Triangular Proposal.

Keywords: Art Teaching. Textbook. Afro-Brazilian and indigenous history and culture.
\end{abstract}

\section{Introdução}

Muitos são os elementos que constituem a memória escolar de cada um, amigos, professores, brincadeiras, broncas, materiais escolares, etc.. Estes últimos, em geral, integram as memórias relativas ao início do ano letivo, quando estão novos e carregados de aromas e ansiedades. Entre eles estão os livros didáticos, por vezes cuidados e folheados com ansiedade e curiosidade. Esses aspectos podem sugerir um momento nostálgico de um tempo distinto do atual, permeado por diferentes tecnologias que vão desde os cadernos impressos até smartphones e tablets.

O livro didático (LD), artefato cultural que permeou a vida de muitas pessoas, constitui neste escrito objeto de pesquisa. Como tal, tem um histórico recheado de críticas que o colocam em uma posição não tão bonita como a acima descrita, e que o apresentam como limitador dos conteúdos e práticas docentes. No âmbito do ensino de Arte escolar, no qual nem sempre há um currículo definido e onde, muitas vezes, a carência de professores específicos é suprida por professores com formação distinta daquela relacionadas à disciplina Arte, é importante refletir sobre o modo de utilização dos livros didáticos e seu conteúdo neste contexto.

Sob um ponto de vista favorável aos materiais didáticos, Antoni Zabala (1998) alerta que o livro didático configura um dos tipos de materiais curriculares que "proporcionam ao educador referências e critérios para tomar decisões, tanto no planejamento, como na intervenção direta no processo de ensino, aprendizagem e sua avaliação" (p. 167). O autor alerta para a importância desse material nos processos de ensino e aprendizagem realizados na escola, entendendo que este não constitui elemento único no planejamento e prática. Assim, outros materiais, ou mesmo livros distintos daquele adotado pelo professor, podem e devem ampliar os processos pedagógicos.

Vale lembrar, aqui, que o livro didático, assim como os outros materiais produzidos, traz consigo o resultado das escolhas feitas pela sua autoria. $\mathrm{O}$ autor, mesmo que ao desenvolvê-lo tenha por referencial os documentos legais que orientam a educação nacional, no caso dos livros didáticos, faz escolhas pessoais dos conteúdos que nele estarão disponibilizados. Sendo assim, o autor ao desenvolver um livro, faz antes uma curadoria dos elementos que o integrarão. Neste sentido, é preciso compreendê-lo como uma opção, e não a única referência para a produção dos currículos. Deste modo compreende-se a importância em integrar a ele outros materiais, que podem apresentar diferentes características e pontos de vista.

No Brasil, o Ministério da Educação, por intermédio do Programa Nacional do Livro Didático (PNLD), busca oferecer subsídio para o "trabalho pedagógico dos professores por meio da distribuição de coleções de livros didáticos aos alunos da educação básica" (Extraído em http://portal.mec.gov.br/pnld/apresentacao em 05 de agosto de 2016). Com isso, a cada ano as escolas públicas recebem gratuitamente novos livros didáticos para alunos e professores. Em 2015, o PNLD 
incluiu pela primeira vez, na sua relação de opções, livros para a disciplina Arte. Livros didáticos para este componente curricular vêm sendo produzidos há muitos anos, contudo, não são comumente adotados pelas escolas. Sendo assim, apenas alguns professores os recebiam como divulgação ou adquiriam por conta própria e, utilizavam-no como apoio em seu planejamento. Desta forma, pouco ou quase nenhum material didático específico de Arte chegava até a escola. No momento em que existe a possibilidade de, por meio do PNLD, fazer uso do livro didático, esta situação pode ser vislumbrada como um modo de aproximar, ainda mais, as crianças do conhecimento artístico. Afinal, como livro didático este artefato adentrará a casa de muitas crianças, podendo expandir os saberes e interesses acerca da Arte para aqueles que com ele convivem.

Com esta expectativa, intriga saber que referencias os livros didáticos selecionados para compor as opções para a disciplina Arte do PNLD estão apresentando. Importante lembrar que, de acordo com a legislação vigente, Arte configura componente curricular obrigatório em todos os níveis da Educação Infantil e Ensino Fundamental constituído por diferentes modos de produção, quais sejam: Música, Artes Visuais, Dança e Teatro. Além disso, a Lei 11.645 de 10 de maio de 2008 aponta a obrigatoriedade do ensino da cultura Afro-brasileira e Indígena, sendo parte do conteúdo curricular da disciplina Arte, entre outras sugeridas na legislação vigente.

Tendo em conta as características da disciplina Arte, que envolve os diferentes modos de produção e, em cada um deles, seus conteúdos específicos, busca-se neste escrito delimitar o campo de observação na temática da História e Cultura Afro-brasileira e Indígena. Tal assunto, já está presente nos documentos legais desde 2008, contudo, ainda é tema esporadicamente trabalhado nas práticas escolares, segundo observações informais. Neste sentido, intentouse visualizar nas produções didáticas aprovadas e disponibilizadas por instâncias governamentais, que estão também relacionadas à elaboração dos documentos legais, as possibilidades de trabalho e como tal temática é apresentada.

\section{Livros didáticos PNLD 2017 - Arte}

O ensino de Arte no cenário brasileiro traz uma história marcada por muitas lutas, a busca por igualdade e respeito no espaço escolar é apenas uma delas. As propostas que norteiam o ensino de Arte na escola buscam ampliar os sentidos e a compreensão sobre o mundo, de modo que cada um possa reconhecer-se como agente potencial na sua constituição. Neste sentido, estão integradas ações que visam o conhecimento amplo de sua cultura e daquelas que são distintas da sua, de modo que todos possam reconhecer os aspectos multiculturais nos quais estão integrados. Neste ínterim estão as temáticas das culturas afrobrasileira e indígenas, que são parte fundamental na compreensão das culturas brasileiras. Tais temas foram ignorados por muito tempo e hoje, por força da lei, devem estar presentes no currículo escolar. Diante deste contexto, se buscou lançar um olhar sobre as produções didáticas disponibilizadas para as escolas pelo PNLD, para o ensino de Arte. Para esta observação foram utilizados livros didáticos de Arte apresentados no PNLD 2017, contemplado por duas coleções desenvolvidas para os anos finais do Ensino Fundamental (EF) das escolas públicas brasileiras as quais serão apresentadas e comentadas a seguir.

Para sistematizar a observação optou-se por, inicialmente fazer uma busca nos títulos elencados nos sumários de cada volume, buscando encontrar neles referenciais sobre a temática buscada neste trabalho. Além disso, tendo em vista a Proposta Triangular (Barbosa, 2005), proposta que vem sendo utilizada nas práticas contemporâneas do ensino da Arte, a qual integra processos de apreciação (leitura de imagem), contextualização (história da arte) e fazer artístico nas práticas pedagógicas, entende-se ser importante observar se os materiais referenciais do PNLD dão suporte a tal prática. Deste modo, foram buscados referenciais textuais verbais que deem suporte para a contextualização, referenciais de objetos artísticoculturais como repertório para apreciação e, ainda, referenciais para práticas do fazer artístico. Ainda, se observou a presença de possíveis materiais complementares citados ou sugeridos de possível utilização pelos professores.

\section{Observação - Coleção Projeto Mosaico}

A Coleção Projeto Mosaico, desenvolvida pela editora Scipione em 2015, está organizada em quatro volumes, cada um correspondente a um dos anos finais do EF. Cada livro está organizado com uma introdução e seis capítulos divididos em oito partes distintas que abordam textos, imagens, artistas, instigam debates, apresentam técnicas e atividades, e ainda, ao final há uma parte denominada "Projetos" na qual é proposto um projeto coletivo. Além disso, de acordo com informações obtidas nos próprios livros, cada volume é estruturado sob uma temática distinta e ênfase de produção artística, porém as Artes Visuais e a Música estão presentes nos quatro volumes, as quais apoiam os subtemas e conteúdos desenvolvidos. Os volumes estão assim organizados: $6^{\circ}$ ano - Corpo / Dança; $7^{\circ}$ ano - Cidade / Artes Visuais; $8^{\circ}$ ano - Planeta / Música; e $9^{\circ}$ ano Ancestralidade / Teatro.

Volume $-6^{\circ}$ ano. O livro desenvolvido para o $6^{\circ}$ ano, cuja temática está centrada no corpo, tem como ênfase a Dança. Na observação realizada, notou-se que seu sumário apresenta, um item sob o título "Pintura corporal nos povos indígenas". Um olhar no material em busca de repertórios tendo em vista referenciais para apreciação, observou-se que sobressaem as imagens, ao todo foram elencadas 19 imagens, dentre as quais 13 estão relacionadas à cultura afro-brasileira e seis à cultura indígena. Tais imagens estão distribuídas ao longo do livro e independem do conteúdo verbal a ela relacionado. Assim, foram consideradas imagens que em sua composição apresentassem ou representassem as culturas em questão. Para além das imagens, observouse a citação de outros três objetos passiveis de apreciação, dois deles referem-se a canções, sendo 
destas, uma relacionada à cultura indígena e a outra à cultura afro-brasileira. Outra produção sugerida constitui um audiovisual que reporta à cultura indígena. Buscou-se também referenciais para contextualizar tais temas, ou seja, conteúdos textuais verbais que podem ser base para o desenvolvimento dos temas buscados. Neste critério foram localizados 14 itens e subitens dos quais seis reportam a cultura indígena e os oito restantes à cultura afro-brasileira. Sob a busca de sugestões de práticas do fazer artísticos relacionadas às temáticas buscadas foram encontradas duas sugestões relacionadas à cultura indígena. Por fim, buscou-se por materiais complementares que poderiam estar sugeridos no volume em questão, neste âmbito foram localizados dois livros sobre cultura afro-brasileira e dois sites sobre cultura indígena. Neste volume, nota-se que o sumário apenas apresenta a cultura indígena em seus títulos. Contudo, de um modo geral, aspectos acerca da cultura afro-brasileira sobressaem em comparação à cultura indígena, especialmente em opções para apreciação de imagens. No que concerne referenciais para contextualizar ambas temáticas estão apresentadas em quantidade semelhante. Já as opções de práticas artísticas relacionadas à cultura afro-brasileira são ausentes.

Volume $-7^{\circ}$ ano. O livro destinado ao $7^{\circ}$ ano tem por tema a Cidade e, de acordo com a apresentação do material sua ênfase artística é Artes Visuais. Neste volume não se observou nenhum título apresentado no sumário relacionado a temática buscada. No que concerne o interior do livro e, buscando por repertórios, observou-se apenas possibilidades imagéticas, o volume apresenta três imagens, sendo uma delas relacionada a cultura indígena e duas referenciando a cultura afrobrasileira. Novamente, é preciso dizer que tais imagens não foram observadas no seu contexto, e sim a sua composição e suas relações com a temática que se busca. Como elemento textual verbal que pode subsidiar a contextualização, encontrou-se cinco itens, dentre os quais um aborda a cultura indígena e dois a afrobrasileira. No que concerne sugestões de práticas do fazer e materiais complementares não foram encontrados dados. Nota-se que as opções de apreciação e que podem promover a discussão dos temas buscados é pequena. Um pouco maior é a possibilidade de contextualização. Sendo assim, nota-se que são pequenas as possibilidades apresentadas e nenhuma possibilidade que estimule a ação prática.

Volume $-\mathbf{8}^{\circ}$ ano. O livro destinado a $8^{\circ}$ ano aborda a temática artística Música sob a temática Planeta. Em busca no sumário deste volume não se encontrou nenhuma referência ao tema buscado. Em olhar no interior do volume, buscando possibilidades de objetos para apreciação foram elencados sete possibilidades, uma delas musical, e seis imagéticas, sendo uma referência indígena e cinco afro-brasileiras. Lembrando que as imagens, não estão necessariamente relacionadas ao tema buscado, elas apenas possuem em sua composição elementos imagéticos relacionados aos temas. Foram encontradas três opções que poderiam contextualizar as temáticas indígena e afro-brasileira, dentre as quais uma está relacionada à cultura indígena e outra à cultura afro-brasileira. Em busca de possibilidades de ações práticas não foram encontradas alternativas que referenciam as culturas supracitadas. Como materiais complementares ou sugeridos que estão para além do que é apresentado no volume em questão, dois sites foram citados como possibilidade de aprofundamento e/ou local de informações. Neste volume, nota-se que as possibilidades de uso de referenciais sobre as culturas indígena e afro-brasileira não estão evidentes. Poucas são as referências de apreciação e menores ainda as opções de contextualização. Ações são ausentes e poucos são os materiais sugeridos.

Volume $-9^{\circ}$ ano. $\mathrm{O}$ volume desenvolvido para o $9^{\circ}$ ano tem por ênfase artística o Teatro sob a temática Ancestralidade. $\mathrm{O}$ volume não apresenta em seu sumário nenhum título que referencia algum dos temas buscados. Em olhar sobre as possibilidades de apreciação disponíveis no interior no livro foram encontradas 15 possibilidades, dentre as quais dez referem-se a cultura afro-brasileira, uma de Dança, outra musical e oito imagéticas. As outras cinco, relacionadas à cultura indígena são também imagéticas. Três possibilidades de contextualização foram observadas, sendo duas da cultura indígena e uma afrobrasileira. Como possibilidade de referencial para o fazer artístico uma possibilidade, relacionada a cultura afro-brasileira foi observada. Além destes, nenhum material foi sugerido para complementar os temas buscados. Notou-se, neste volume, a ausência de sugestões sobre os temas buscados no sumário, situação que pode parecer estranha visto que a temática geral abordada no livro é ancestralidade, tendo em vista que a cultura brasileira tem na sua origem as culturas que estão neste texto em questão. Observou-se um número interessante no que concerne à apreciação, abordando ambas temáticas. A contextualização também apresenta possibilidades, mesmo que o número de opções não seja tão grande. Outro fato ausente são as opções de materiais complementares, tendo em vista a temática geral do volume.

A observação sobre toda coleção faz concluir que o volume desenvolvido para o $6^{\circ}$ ano apresenta mais possibilidades de referenciais sobre as temáticas pesquisadas, apresentando elementos em todos os quesitos buscados. Observou-se também que ao longo da coleção, não foram apresentados referenciais, relacionados ao tema, e que estão voltados para o teatro, mesmo tendo um volume no qual o teatro é enfatizado. Por coincidência o volume relativo ao teatro é justamente aquele no qual a temática Ancestralidade é abordada. Nota-se um número pequeno de sugestões de propostas para o fazer e que estão relacionadas aos temas. Contudo, vale ressaltar, que ao longo da coleção várias opções de apreciação foram elencadas, muitas delas, a maioria, imagéticas. Fator que já pode ser interessante para a abordagem na aula de Arte.

\section{Observação - Coleção Por toda parte}

A Coleção Por toda parte, desenvolvida pela editora Scipione em 2015, está organizada em quatro volumes, 
cada um correspondente a um ano do Ensino Fundamental. Cada livro é composto por duas unidades divididas em dois capítulos, sendo cada um deles organizado em três temas e alguns tópicos com subtemas e, além disso, complementam cada capítulo, dois tópicos específicos de alguma linguagem artística. Um olhar sobre os volumes desta coleção aponta as seguintes observações acerca da cultura e história afrobrasileira e indígena:

Volume $-6^{\circ}$ ano. $O$ exemplar destinado ao $6^{\circ}$ ano, apresenta em seu sumário um total de 15 títulos ou subtítulos que foram elencados. Quatro deles fazem referência à cultura indígena: "A floresta dos curumins", "A arte dos povos indígenas", "Mais de perto: tramas da arte indígena" e "Palavra do artista: Povo Kaingang", e 11 deles a cultura afro-brasileira: "As semestres da cultura afrodescendente", "A cultura afrodescendente", "Palavra do artista: Mestre Didi", "Palavra do artista: Rosana Paulino", "Palavra do artista: Chico Science", "O maracatu do Chico Rei", "Maracatu moderno", "Palavra do artista: Mestre Salustiano", "Palavra do artista: Manoel Salustiano Filho", "Dançando no ritmo do maracatu" e "Ação e criação: Vamos dançar o maracatu?". Com o objetivo de elencar objetos para apreciação, foram encontradas 34 referências imagéticas, sendo destas 13 relacionadas à cultura indígena e 21 à cultura afro-brasileira, é importante lembrar que as imagens não estão diretamente ligadas ao tema, podem ser apenas utilizadas como ilustrações no livro. Ainda nesta última categoria foram relacionados, um referencial de Dança, quatro musicais e dois teatrais, perfazendo um total de 41 referenciais. Como referencial de contextualização foram elencados oito relacionados aos povos indígenas e 12 à cultura afro-brasileira. Duas propostas de prática do fazer foram observadas, uma delas acerca da cultura indígena e direcionada para as Artes Visuais e outra relacionada a cultura afro-brasileira e no âmbito da Dança. Também foi encontrado no âmbito da cultura afro-brasileira uma sugestão de filme. Neste exemplar foram encontrados vários títulos ou subtítulos relacionados aos temas pesquisados, do mesmo modo, vários referenciais para apreciação e contextualização. Notou-se a sugestão de prática diversificada, possibilitando desenvolver diferentes produções em diferentes modos de produção. Interessantes, também, destacar o filme sugerido, que para além de abordar o tema, apresenta uma outra forma de produção artística, o cinema.

Volume $-7^{\circ}$ ano. O livro desenvolvido para o $7^{\circ}$ ano apresenta em seu sumário um título relacionado à cultura indígena, "Projeto Nande Reko Arandu Memória Viva Guarani". Um olhar em busca de elementos para apreciação faz elencar nove itens imagéticos, sendo oito da cultura indígena e um da cultura afro-brasileira, para além disso, três elementos musicais relacionados a cultura indígena e dois sobre a cultura afro-brasileira. Três elementos de contextualização foram elencados, dois deles referem-se à cultura indígena e um à cultura afro-brasileira. Nenhuma sugestão de proposta de fazer foi relacionada, da mesma forma, nenhuma sugestão de material complementar. Nota-se neste volume um número interessante de opções para apreciação, contudo apenas dois modos de produção artística, apenas Artes Visuais e a Música são contempladas. Interessante ressaltar a ausência de propostas práticas, assim como de materiais complementares.

Volume $-8^{\circ}$ ano. No exemplar elaborado para o $8^{\circ}$ ano foi apresentado em seu sumário três itens relativos à cultura afro-brasileira, "Batucadas e batidas", "Batuque de bambas" e "Batucada". Ao longo do volume 11 imagens que fazem referencia aos temas buscados foram localizadas, cinco delas relacionadas a cultura indígena e seis delas a cultura afro-brasileira. Ainda, como elemento de contextualização, foram elencados cinco itens, dois indígenas e três afro-brasileiros. Também foi destacada uma sugestão de ação prática relacionada à cultura afro-brasileira e duas sugestões de materiais complementares ligadas à cultura indígena, dentre elas uma é um livro e a outra um filme. Observase neste material que todos os quesitos foram observados, contudo há ausências como a temática indígena no sumário e nas práticas, assim como em objetos de observação distintos de imagens, do mesmo modo nota-se esta ausência sob a temática afrobrasileira também.

Volume - $9^{\circ}$ ano. O livro elaborado para o $9^{\circ}$ ano não apresenta em seu sumário qualquer título que faça referência aos temas procurados. Da mesma forma não foram elencadas opções para contextualização, propostas de fazer e materiais complementares. Apenas foram destacadas referências imagéticas, três indígenas e nove afro-brasileiras. Neste volume, observou-se que os temas não foram desenvolvidos, apenas algumas imagens foram dispostas.

De um modo geral, pode-se dizer que esta coleção "Por toda parte" aborda em vários momentos elementos sobre as temáticas relacionadas à cultura indígena e afro-brasileira. Destaca-se o $6^{\circ}$ ano como aquele no qual mais recorrências foram elencadas e, além disso, de um modo bem amplo abrangendo vários quesitos. Nota-se que conforme os anos avançam diminui a incidência de elementos abordando os temas buscados, finalizando a coleção com o $9^{\circ}$ ano e com pouquíssimas opções. Nota-se uma pequena opção de propostas de fazer e do mesmo modo as sugestões de materiais.

\section{Comentários sobre as observações}

Após uma observação nos materiais é possível verificar, sob aspecto quantitativo, que a coleção Por toda parte traz mais elementos abordando as temáticas desejadas do que a coleção Mosaico. Nota-se também, que a Coleção Mosaico traz em seus elementos destacados um número maior de aspectos indígenas, ao contrário da coleção Por toda parte, que traz mais aspectos relacionados a cultura afro-brasileira.

Ambas as coleções apresentam o mesmo número de sugestões de práticas de fazer, denominadas em uma das coleções como ações criativas. Atenta-se ao fato de apresentarem poucas sugestões de materiais complementares. Destaca-se ainda, que em ambas as coleções o $6^{\circ}$ ano é aquele no qual há um número maior 
de referências, tendo os outros anos subseqüentes, um número menor de recorrências.

\section{Considerações finais}

As temáticas relacionadas às culturas indígena e afrobrasileira integram aspectos da formação cultural do Brasil, e, por isso, já deveriam fazer parte dos currículos escolares, independente de disciplina e orientação legal. Contudo, ao longo da construção da história e cultura brasileira tais culturas foram ignoradas e banidas, ressaltando apenas algumas culturas de povos que para o Brasil vieram. A intenção deste escrito é evidenciar esta temática a partir dos materiais didáticos que vêm sendo destinados e disponibilizados às escolas publicas brasileiras. De forma geral, há um modo já construído para a utilização dos materiais didáticos, em especial o livro didático. Este modo constitui em segui-lo do inicio ao fim de modo a completar seu estudo ao término do ano letivo. Contudo, opta-se por entendê-lo, aqui, como um referencial curricular. E mesmo sendo disponibilizado aos alunos, compreende-se que o livro pode ser utilizado de diferentes maneiras. Assim como, a ele podem ser agregados outros materiais e, ao mesmo tempo, este constituir um elemento a ser agregado em outros. Esta flexibilidade precisa ser compreendida e tomada como rotina no processo pedagógico, possibilitando aos alunos a compreensão de que os livros didáticos não são o único referencial a busca pelo conhecimento pode ser realizada em diferentes locais.

Sob este entendimento foi realizada uma observação sobre os livros didáticos de Arte disponibilizados às escolas pelo PNLD 2017. Atenta-se que não foram realizados estudos aprofundados acerca dos conteúdos, foi realizada uma observação como se busca por referenciais gerais. Entende-se que este é o primeiro passo de uma pesquisa que pode ser desdobrada.

$\mathrm{Na}$ observação realizada evidenciou-se, ligeiramente, que os aspectos apresentados nos livros estão voltados às produções artístico-culturais das culturas em questão, aspectos nos quais observou-se um número significativo de elementos. Ressalta-se uma preferência por desenvolver estes conteúdos com mais ênfase nos $6^{\circ} \mathrm{s}$ anos em ambas as coleções.

Este escrito é apenas um olhar inicial e breve sobre tais coleções, evidentemente que os temas abordados na disciplina de Arte são inúmeros, para que não se diga infinitos, seria muita pretensão disponibilizá-los todos aos alunos, e, por isso, são feitas escolhas, para os livros, para os currículos, para os planos. Contudo, pode-se dizer que os livros disponibilizados pelo PNLD, mesmo que, talvez,e não abordem muitos aspectos das culturas indígena e afro-brasileira já aponta para um começo de inserção destas temáticas relacionando-as com outras culturas e com a realidade.

\section{Referências}

Barbosa, A. (2005). A imagem no ensino da arte. São Paulo: Perspectiva.
Brasil. (2013). Diretrizes Curriculares Nacionais Gerais para a Educação Básica. Brasília: MEC.

Brasil. (2003). Lei 10.639. http://www.planalto.gov.br/ccivil_03/leis/2003/L10.6 39.htm..

Brasil. (2008). Lei 11.645 . http://www.planalto.gov.br/ccivil_03/_ato20072010/2008/lei/111645.htm.

Brasil. (1996). Lei de Diretrizes e Bases da Educação Nacional - $\quad$ Lei 9.394. http://portal.mec.gov.br/arquivos/pdf/ldb.pdf.

Programa Nacional do Livro Didático - PNLD. http://portal.mec.gov.br/pnld/apresentacao.

Meira, B.; Soter, S,; Elia,.; Presto, R. (2016). Projeto Mosaico Arte 6o ano. São Paulo: Scipione.

Meira, B.; Soter, S,; Elia,.; Presto, R. (2016). Projeto Mosaico Arte 7o ano. São Paulo: Scipione.

Meira, B.; Soter, S,; Elia,.; Presto, R. (2016). Projeto Mosaico Arte 8o ano. São Paulo: Scipione.

Meira, B.; Soter, S,; Elia,.; Presto, R. (2016). Projeto Mosaico Arte 9o ano. São Paulo: Scipione.

Utuari, S.; Kater, C.; Fischer, B.; Ferrari, P. (2015). Por toda parte 6o ano. São Paulo: FTD.

Utuari, S.; Kater, C.; Fischer, B.; Ferrari, P. (2015). Por toda parte 7o ano. São Paulo: FTD.

Utuari, S.; Kater, C.; Fischer, B.; Ferrari, P. (2015). Por toda parte 80 ano. São Paulo: FTD.

Utuari, S.; Kater, C.; Fischer, B.; Ferrari, P. (2015). Por toda parte 90 ano. São Paulo: FTD.

Zabala, A. (1998). A prática educativa: como ensinar. Porto Alegre: ARTMED. 